\title{
Research on Related Questions about Optimized Design of Earthing Network for Radio Base Station
}

\author{
Jike Liu ${ }^{1, \mathrm{a}}$, Yongshuang Lin ${ }^{2, \mathrm{~b}}$, Qiang Chen ${ }^{1, \mathrm{c}}$, Zheng Qi ${ }^{1, \mathrm{~d}}$, Zhigang Wang ${ }^{1, \mathrm{e}}$ \\ ${ }^{1}$ China Information Technology Designing \& Consulting Institute Co., Ltd. \\ Zhengzhou, China \\ ${ }^{2}$ China Guangdong Mobile Communication Co., Ltd. \\ Guangzhou, China \\ Email: ${ }^{a}$ liujike@dimpt.com, ${ }^{b} 13902880005 @ 139 . c o m,{ }^{c}$ chqg007@dimpt.com, \\ dqizheng@dimpt.com, ${ }^{\mathrm{e}}$ wangzg06@dimpt.com
}

\begin{abstract}
Some research have explained the difference of effect between power frequency current with lightening current injecting into earthing network. The surface of the earthing body can be approximately regarded as equipotential surface in the case of power frequency no matter how large the area of an earthing network is, so the total area of the earthing network can be made full use of. This case is different when the earthing body is in contact with the lightning current. The potential of the earthing network is not equal by the agency of the inductance of the earthing body, and the farther away from the point where the lightning current is introduced, the lower the potential on the earthing body. That is only the earthing network around the point where the lightning current is introduced plays a part in dissipating energy, and moreover, the energy dissipation is in proportion to the potential distribution in this area. The technology of Optimized Design of Earthing Network has been introduced in other article and this article concentrates on some key questions about the purpose of Earthing, related parameter affecting earthing network, relation between the number of earth network grids and earthing resistance, characteristics of lightening current, the impulse equivalent radius of the earthing network, relation Between Mesh and Equipotential Contact Coefficient.
\end{abstract}

Keywords- RBS; lightening; Optimized Design

\section{INTRODUCTION}

The surface of the earthing body can be approximately regarded as equipotential surface in the case of power frequency no matter how large the area of an earthing network is, so the total area of the earthing network can be made full use of. But in the case of lightening impulse current, only a small part of earthing network can be made use. Using the theory of available area for the bleeding of lightening current instead of the requirement of earthing resistance, changes the long-term innate perception of seeking lower earthing resistance, which is more rational. The magnitude of earthing resistance has not any influence on the parameter of RBS equipments and signal transmission, which has been proved on a large amount of operating RBS, but the increase of earthing resistance may introduce over-high contact voltage and step voltage and so it is essential to research some questions and parameters about Optimized Design of Earthing Network.

\section{PURPOSE OF EARTHING FOR RBS}

The purpose of earthing for RBS is connected with five aspects such as:

1) According to the IEC60950 Safety Specifications of Information Technology Equipment, the communication equipment using the AC/DC converter falls into the category of equipment of basic insulation. The exposed conductive parts of such a type of equipment must be reliably earthed to prevent the voltage from damaging the human body in the event of equipment failure.

2) In view of the impact on the earth loop current, the analog communication equipment primarily adopting the detachable components must be earthed independently. But for the digital communication equipment primarily adopting the Large-Scale Integrated circuit (LSI), the working earth ground may and must be combined with the protection ground due to the poor anti-surge capability of the internal components though the equipment features strong anti-interference capability.

3) For DC system ( $-48 \mathrm{~V}$ is the DC positive ground, and + 24V DC negative ground), the earthing should be targeted on at least the following two purposes:

a. Security. To prevent the hazardous voltage from striking the human body in the event of power system failure.

b. Equipment protection. To prevent the hazardous voltage from damaging the equipment in the event of power system failure.

4)The equipment should connect with the protection ground directly to prevent the static from damaging the equipment.

5)The RBS should connect with the protection ground directly to enable discharge of lightning energy introduced in the system.

Through the above earthing purposes, it is quite obvious that the earthing resistance is based on the principle that the hazardous voltage should not be detrimental to the human body and equipment. That is, the potential fall of the faulty current cannot impose danger on the person in contact with the equipment or on the equipment itself in the case of short-circuit of power system. 


\section{DifFERENCES BETWEEN LARGE CURRENT INJECTING INTO EARTH IN HV STATIONS AND SMALL CURRENT INJECTING INTO EARTH IN RBSS}

The Power Department regulates that the power frequency earthing resistance should not exceed $0.5 \Omega$, which is to limit contact voltage and step voltage under the permitted range and ensure the safety of personal and equipments in the event of power system failure in $\mathrm{HV}$ stations.

The differences between HV Stations and RBSs are:

1)In the case of short-circuit of power system ,the short-circuit current is up to dozens of kilo-ampere and the cut-off duration is under $0.5 \mathrm{~s}$. The injecting current is very large and the cut-off duration of breaker is on the order of a second, and further more, the very rapid cut-off is difficult to control.

2) In the case of short-circuit of RBS, the short-circuit current is only dozens of ampere and is not exceed thirty-ampere generally.

3) The value of earthing resistance of RBS can be calculated according with the permitted earth rise potential (2000V) in HV stations.

$$
\begin{gathered}
\mathrm{IR}=2000 \\
\mathrm{R}=2000 / \mathrm{I}=2000 / 30=66 \Omega
\end{gathered}
$$

In a particular situation, the permitted earth rise potential could be $5000 \mathrm{~V}$. The value of earthing resistance of RBS could be:

$$
\mathrm{R}=5000 / \mathrm{I}=5000 / 30=166 \Omega
$$

On the other hand, RCD should be installed in the power distribution system of RBS for the reason of electric safety.

\section{PARAMETERS AFFECTING EARTHING NETWORK}

\section{A. Relationship between earthing network and earthing} resistance

The earthing network is designed for the mobile site to obtain the lowest earthing resistance on the path of lightning current that flows to the earth, and retain the electrical potential generated into a secure range in the area it protects.

An earthing network consisting of multiple earthing bodies can be approximately treated as an isolated panel. The capacitance of the earthing network depends on the area of the panel, and the vertical earthing body attached to the panel has a limited length $(2-3 \mathrm{~m})$, and is not enough for changing the geometrical size that is decisive to the size of capacitance. Therefore, the capacitance does not increase much, that is, the earthing resistance drops little. The earthing resistance $\mathrm{R}$ here can be expressed in the following formula:

$$
R=\frac{1}{C} \frac{\varepsilon \oint S^{*} E^{*} d s}{1 / \rho \oint S^{*} d s}=\frac{\rho \varepsilon}{c}
$$

Where, $\mathrm{R}$ — The earthing resistance of the earthing body $(\Omega)$.

$\mathrm{C}$ - The capacitance (F) of the earthing body.

$\rho \_$The earth resistivity $(\Omega . m)$.

\section{1 \\ $\varepsilon-\varepsilon_{\mathrm{r}} 4 \pi \times 9 \times 10^{9} \quad$ refers to the dielectric factor of} the earth $(\mathrm{F} / \mathrm{m})$.

$\varepsilon_{\mathrm{r}}-$ Relative dielectric factor of the earth.

This important formula shows that the increase of the earthing network area is crucial to the drop of earthing resistance. The capacitance may increase dramatically, that is, the earthing resistance may drop effectively, only when the length of the attached vertical earthing body is close to the equivalent radius of the earthing network and when the panel borders on a hemisphere. Even in such a case, the earthing resistance only shows a drop of $36.3 \%$, and this can be deduced from the following formula:

Suppose the earthing network is equivalent to a hemisphere with the depth of burial of 0 , radius of cross section $r$ and height of the hemisphere $R_{1}=\rho / 4 r: R_{2}=\rho / 2 \pi r$

$$
\mathrm{R}_{1} / \mathrm{R}_{2}=0.637
$$

It is thus obvious that the earthing resistance is related to the area of the earthing network, and the vertical earthing body of $2-3 \mathrm{~m}$ attached to the earthing network does not help much in reducing the earthing resistance. With respect to the design of the earthing network, the idea of thickening the vertical earthing bodies to reduce the earthing resistance is unadvisable. The earthing network should be regarded as a two-dimensional panel in a macro sense. No matter how thick the vertical earthing bodies are, (compared with the equivalent radius of the earthing network, the length of the vertical earthing body should be at least one order of magnitude smaller) even if they are as thick as a solid steel sheet with the thickness of $2-3 \mathrm{~m}$, the earthing resistance does not drop much.

\section{B. Relation Between Number of Grids and Earthing Resistance}

The earthing bodies in close proximity to each other cannot be made full use of. The shielding effect between the earthing bodies arises out of overlap of electrical field when the current flows to the earth (The resistance of the earthing body depends on the resistivity of the soil around the earthing body. The overlap of the above electrical fields results in the uneven current density and decrease of effective area of the soil around each earthing body, or the increase of drift resistance). When the earthing bodies are configured in a mode of concentric circles or the earthing network in rectangular grids, the utilization of the earthing body is particularly low as a result of the mutual shielding of the earthing bodies. And the utilization coefficient of the vertical earthing bodies at intersections of grids is only $0.15-0.20$. The outer ring of the earthing body rather than the number of earthing bodies in the grid is influential to the earthing resistance, so it is neither cost-effective nor practical to add the number of grids in the earthing network in order to reduce the earthing resistance.

According to related statistics, if the earthing resistance $\mathrm{R}$ of a common joint ground is $100 \%$, the earthing resistance of solid steel sheet will be about $90 \% \mathrm{R}$, that of hollow ring earthing network (with earthing bodies at the 
periphery) will be $110 \% \mathrm{R}$, and that of building foundation (the foundation with reinforcement is generally deep, but gaps exist in the building) will be $80 \% \mathrm{R}$. It is evident that the earthing resistance of the earthing network does not drop significantly by thickening the horizontal earthing bodies and increasing the vertical ones.

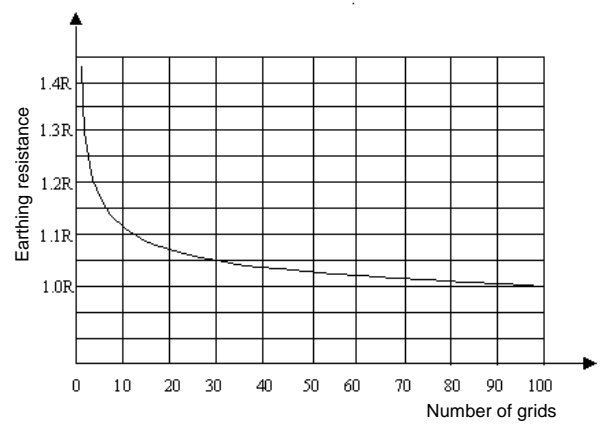

Figure 1. Relation between number of grids and earthing resistance

As described in the EMC Design Manual (AFSC-DH1-4) released in the U.S., "in view of the economic benefit of the design, extend the area of the earthing network as possible so as to reduce the earthing resistance while keeping the number of meshes within 16". This accords with the test results of Ministry of Water Conversancy and Electric Power of China. When number of the grids of earthing network are more than 16, the earthing resistance drops very slowly. For example, the earthing resistance of a square earthing network with 16 grids drops $23 \%$ compared with that with 2 grids, and only $10 \%$ compared with that with 4 grids. The relation between the number of grids and earthing resistance is shown in Figure 1 ( $\mathrm{R}$ in the figure refers to the earthing resistance of the panel).

It is obvious that the way to lower the earthing resistance by increasing the number of grids of the earthing network is not recommended for design optimization. The use of the earthing body with more than 16 grids to expand the area of the earthing network will achieve better effect in lowering the earthing resistance.

\section{Characteristics of lightening current, the impulse equivalent radius of the earthing network}

For the mobile site located on the mountain, it is impractical to realize small earthing resistance (for example, $5 \Omega$ ) within a limited area. But we may enable the potential in every parts of the mobile site to rise accordingly and balance the impulse voltage between devices in the office to strengthen discharge of lightning current in the event of lighting stroke by way of equalizing earth potential, adopting joint ground and improving the layout of earthing cable. This raises the strict restriction over the earthing resistance of the mobile site, and at the same time involves the trade-off between the safety effect of the ground potential and the expense necessary to achieve a very low resistance.

The resistance, generated when the earthing body of one lightning rod is in contact with the lightning, significantly differs from the earthing resistance of the DC and power frequency current. The physical process induced by the lightning in the soil also differs quite a lot from that generated by the power frequency current. The major difference between them lies in the formation of lightning and the characteristic of the soil to transmit the high frequency electromagnetic wave. The lightning stroke is characteristic of the shock wave with tremendously high current. When the electric field intensity around the earthing body exceeds the breakdown strength of the soil because of the large amplitude of the lightning current, the arc is generated, achieving the effect of expanding the area of the earthing network actually. Therefore, the earthing resistance of the earthing network drops by the agency of the lightning current.

The lightning current exhibits the following characteristics when dissipating energy to the soil through the earthing body:

- The lightning current produces a strong electrical field around the earthing body due to large current amplitude when flowing to the soil through the earthing device. And the soil resistivity is also affected by the electrical field intensity. With the increase of the electrical field intensity, that is, with the increase of current density, the soil resistivity drops.

- The lightning current is equal to the high frequency power supply. In addition to the resistance and conductance, the inductance and capacitance of the earthing body also have an impact on the impulse impedance. The impact degree is dependent upon the shape of the earthing body, waveform and amplitude of the impulse current, and dielectric factor $\varepsilon_{\mathrm{r}}$ and earth resistivity $\rho$.

- Unlike the DC and power frequency current, the impulse current does not penetrate deep earth stratum and only flows in the shallow soil due to the skin effect of the high frequency current.

- When the electrical field intensity around the earth body reaches certain value after the lightning current flows to the soil through the earthing device, the voltage is non-linear with the current.

Therefore, when the impulse current or lightning current dissipates energy to the earth through the earthing body, the impulse earthing resistance rather than the power frequency earthing resistance is used to measure the effect of impulse earthing. The impulse earthing resistance is the proportion of the impulse voltage amplitude of earthing device to the impulse current. The above definition shows that the impulse earthing resistance carries no physical meaning because the impulse voltage amplitude and current amplitude does not occur simultaneously (by the agency of the inductance of the earthing body, the former occurs prior to the latter). But this definition can be used to figure out the impulse voltage amplitude when the impulse current is dissipated through the earthing body if the impulse current amplitude and impulse resistance are known.

The surface of the earthing body can be approximately regarded as equipotential surface in the case of power 
frequency no matter how large the area of an earthing network is, so the total area of the earthing network can be made full use of. A lot of earthing bodies constitute a mesh earthing body in the earth ground. The impulse equivalent radius of the earthing network is a constant by the agency of the impulse current when the earth resistivity and dielectric factor are definite. The impulse equivalent radius, however, is much smaller than the equivalent radius of the earthing network at power frequency, that is, only a small area of the earthing network is made use of in the presence of impulse current. The earthing bodies, however, are made full use of in the case of power frequency because all earthing bodies contribute to the current dissipation due to the equal potential in the earthing network. This explains why the earthing resistance is in reverse proportion to the square root of the earthing network area. This case is different when the earthing body is in contact with the lightning current. The potential of the earthing network is not equal by the agency of the inductance of the earthing body, and the farther away from the point where the lightning current is introduced, the lower (even 0 ) the potential on the earthing body. The potential decreases based on exponential curve. Only the earthing network around the point where the lightning current is introduced plays a part in dissipating energy, and moreover, the energy dissipation is in proportion to the potential distribution in this area.

\section{Relation Between Mesh and Equipotential Contact Coefficient}

The joint ground and equipotential of RBS aim to reduce the maximum contact potential difference in the earthing network (distributed potential is formed on the surface of the earth when the current flows through the earthing device. And the potential difference between the shell of equipment and a point $0.8 \mathrm{~m}$ horizontally away from the equipment, or between the floor and a point $1.8 \mathrm{~m}$ vertically away from the floor is called contact potential difference. The voltage borne by the human body after the contact with these two points is called the maximum contact voltage). The maximum contact potential on the surface of the earthing network can be calculated through the following formula:

$$
\mathrm{E}_{\mathrm{jm}}=\mathrm{K}_{\mathrm{j}} \mathrm{E}_{\mathrm{m}}
$$

Where, $\mathrm{E}_{\mathrm{jm}} \longrightarrow$ Maximum contact potential (Unit: V).
$\mathrm{K}_{\mathrm{j}}$-Contact coefficient

$\mathrm{E}_{\mathrm{m}}$ - Potential of earthing device (Unit: V).

Figure 2 shows the relation between the maximum contract coefficient $\mathrm{E}_{\mathrm{jm}}$ and the number of grids of earthing network.

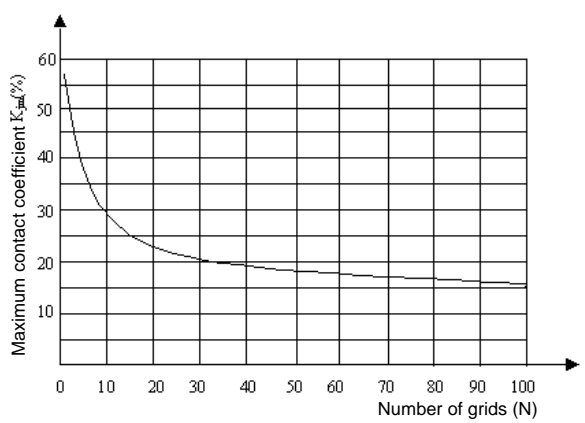

Figure 2. Relation between the maximum contact coefficient $\mathrm{E}_{\mathrm{jm}}$ and number of grids $\mathrm{N}$

(Area of earthing network $=40 \times 40 \mathrm{~m}$; diameter of earthing body $\mathrm{d}=0.02$ $\mathrm{m}$; depth of burial $\mathrm{h}=0.6 \mathrm{~m}$ )

It is thus evident that the maximum contact coefficient exhibits similar drop gradient as the number of grids increases, so it is not recommended to lower the contact coefficient and earthing resistance by increasing the number of grids. The grid of earthing network, in general, can be $3 \times 3 \mathrm{~m}^{2}$ or $5 \times 5 \mathrm{~m}^{2}$. Certainly, onsite measurement and check by use of impulse current are recommended.

In addition, the floor in the equipment room generally adopts a floor structure of high resistivity with average breakdown strength far higher than that of soil, and also restricts the energy that passes through the human body. A layer of insulating rubber sheet of 3-5 $\mathrm{mm}$ thick can be laid on the floor to enhance the arc strength of the floor.

\section{REFERENCES}

[1] Liu Jike, Zhanle, "Study on Radio Base Station Earthing", EMC2004, 2004.

[2] Liu Jike, "Optimized Design of microwave station Earthing Network", Designing Techniques of Posts and Telecommunications, October, 1992 . 